\title{
Emotional distress and coping strategies in COVID-19 anxiety
}

\author{
Mona Vintila $^{1} \cdot$ Otilia loana Tudorel ${ }^{1}\left[\right.$ - Adelina Stefanut ${ }^{1} \cdot$ Alexandra Ivanoff $^{1} \cdot$ Venera Bucur $^{2}$
}

Accepted: 30 December 2021

(c) The Author(s), under exclusive licence to Springer Science+Business Media, LLC, part of Springer Nature 2022

\begin{abstract}
The present study aims to identify psychological factors affected by the COVID-19 pandemic given the information we have about reactions during previous pandemics, which documented features of anxiety, depression and post-traumatic stress disorder. We investigated the relationship between health anxiety, symptoms of depression, anxiety and stress, and coping mechanisms in the general population and among students. The study was conducted on Romanian population $(n=759)$, aged between 18-70 years old $(M=33.24)$, general population $(n=485)$, and students $(n=274)$. The results showed that the general population is more anxious when confronted with the new virus compared to students $(t(757)=1.902, p<.05$, $p=.029)$. Following the analysis of the hierarchical regression, the results revealed that when controlling the health anxiety variable, a high level of anxiety symptoms and stress, and a low level of depression symptoms could predict anxiety for COVID-19 $\left(R^{2}=.070, F_{\text {change }}(3,754)=16.759, p<.001\right)$. Also, we found that maladaptive strategies are the ones which explain the relationship between health anxiety and COVID-19-related anxiety $(95 \% \mathrm{CI}=.011-.057)$. The results of this study bring extra knowledge and shed new light on the psychological aspects of the current sanitary crisis and contribute to the understanding of the way people relate to this disease.
\end{abstract}

Keywords COVID-19 anxiety $\cdot$ Emotional distress $\cdot$ Maladaptative coping strategies $\cdot$ Depression $\cdot$ Anxiety

\section{Introduction}

On January 30, 2020 the World Health Organisation declared the 2019-nCoV outbreak to be a Public Health Emergency (IHR, 2020), while COVID-19 was declared a pandemic on Wednesday, March 11, 2020. This is the first pandemic caused by a coronavirus (WHO, 2020a, b, c). On March 16, 2020 in Romania the state of emergency within the whole country was instituted (DPR, 2020). At that moment there were 158 diagnosed cases and no deaths in our country, while at the present moment there are over 7000 cases per day and over 100 deaths per day.

Coronaviruses are a type of viruses with the appearance of a crown. The Latin for crown is corona, so this is the reason for calling them coronaviruses (WHO, 2020a, b, c). The most frequently found signs are similar to the flue, including

Otilia Ioana Tudorel

otilia.tudorel@e-uvt.ro

1 Department of Psychology, West University of Timişoara, Vasile Pârvan Blvd., 300223 Timișoara, Romania

2 Department of Social Work, West University of Timisoara, Vasile Pârvan Blvd., 300223 Timișoara, Romania fever, cough, breathing difficulties etc. These are typical for an easy form, while in more severe cases serious respiratory distress, pneumonia or kidney problems may occur, which can even lead to death (WHO, 2020a, b, c).

Current reported mortality for COVID-19 is of $2.12 \%$, compared to $9.6 \%$ of SARS (8098 cases, 774 associated deaths) and MERS (2494 cases and 858 deaths in 27 countries $-34.4 \%$ (WHO, 2015). SARS and MERS were other outbreaks in the early twenty-first century (Huremović, 2019).

Due to the fact that the authorities' and media's attention has focused on the somatic consequences of the outbreak, much less attention was given to mental health issues. Some previous studies involving other Coronaviruses have found signs of post-traumatic stress disorder, anxiety and depression after SARS infection (Wu et al., 2005). Thus, a high rate of psychiatric comorbidity was found in the aftermath of SARS epidemic, manifested in profound psychological distress (Chong et al., 2004) and Cheng et al. (2004) found symptoms of anxiety and depression. During SARS outbreak studies showed that even people who were not infected reported psychological problems which are associated with younger age and with 
higher levels of self-blame. A study performed on general population after SARS in 2006 found a rate of 3.7\% symptoms of depression (Liu et al., 2020). Furthermore, research on Middle East Respiratory Syndrome (MERS) emphasized that patients affected by it exhibit psychiatric symptoms or have received psychiatric diagnoses and that stress may be associated with depression (Kim et al., 2018).

Therefore, we might conclude that pandemics have both psychological and social effects on society in general. Pandemics contribute to depression, which can be enhanced by isolation and the physical distancing required during pandemics (Banerjee, 2020). Individuals may be afraid of getting sick, dying and they may feel helpless. Also, the fact that schools and businesses are closed during the pandemic contributes to people experiencing negative emotions (Wang et al., 2020). Eisma et al. (2020) have stated that after natural disasters and viral outbreaks mental health issues have increased.

According to Wang et al. (2020), in Wuhan (2020), $10-30 \%$ of the general population was afraid of being infected with influenza during the epidemics, $53.8 \%$ of those assessed considered the psychological consequences of COVID-19 as being moderate or severe; in $16.5 \%$ of cases depression was found, while a much higher percentage, $28.8 \%$, developed anxiety symptoms and $8.1 \%$ were identified with at least moderate levels of stress.

COVID-19 can be linked to various psychological disturbances like anxiety, depression, panic disorder, healthconcerns. The results show a high level of virus anxiety when assessed retrospectively (Cao et al., 2020; Qiu et al., 2020; Zhang et al., 2020). Previous studies have indicated that more than of $50 \%$ of those investigated experienced anxiety during epidemics or pandemics. Recent studies on Chinese population found that between $25-35 \%$ of the subjects present anxiety and a high level of stress (Cao et al., 2020; Wang et al., 2020). Pandemic related anxiety can lead to stress and avoidance, leading to an inefficient preventive behavior which is not useful for the person and leading in turn to negative consequences, for example pessimism and eventually depression (Qiu et al., 2020; Wang et al., 2020). Liu et al. (2020) found that compared to SARS epidemic, COVID-19 has a greater impact on the general population.

The sudden emergence of COVID-19 caused anxiety on a wide international scale as it turned out to be easily transmissible and very contagious, as well as having a very high death toll, this being the reason for receiving so much attention from both health authorities and any type of media or social network.

Stress (Lazarus, 2006) and pandemics (Huremović, 2019) are part of human life but what makes the difference in human functioning is the way people cope with these situations. Coping modalities initiate, maintain and modulate the affective responses of the individuals during stressful events (Lazarus, 1999).

Nevertheless, even if stressful life events are insufficent on their own to lead to health anxiety disorders, stressors can produce arousal-related bodily sensations, which can be misinterpreted by some individuals as indicators of serious disease (Taylor \& Asmundson, 2004).

In other words, the exposure to health-illness related information, ex. by media, even that of healthy people, may lead to high levels of health related anxiety (Asmundson et al., 2010; Taylor \& Asmundson, 2004). Therefore, anxiety can manifest itself in any/all countries where the current pandemic of COVID-19 is spreading (Asmundson \& Taylor, 2020). Studies showed that anxiety was the result of an exaggerated fear associated with the outbreaks, which might be the consequence of exaggerated information spread via media channels about Swine (H1N1) flu, Ebola virus, Zika virus. Studies offering empirical support for this hypothesis have already been conducted (Blakey \& Abramowitz, 2017; Blakey et al., 2015; Wheaton et al., 2012).

Previous studies have revealed that levels of health anxiety increase in situations with high levels of stress and emotional stimulation and that high levels of health anxiety are associated with low levels of cognitive coping and emotion regulation (Görgen et al., 2014). During the 2009 H1N1 virus outbreak, the authors Taha et al. (2014) had found that low levels of tolerance to uncertainty predicted high levels of anxiety, the mediators being represented by coping strategies and stress assessment.

Coping styles refer to the cognitive and behavioral patterns a person uses in order to face external and internal challenges which are too high compared to the resources of the person in cause (Guo et al., 2020). Regulation strategies can be divided in two major groups, one of adaptive coping and maladaptive coping. Maladaptive strategies have been found to be associated with psychological problems. There are several studies which established a connection between this type of strategies and all facets of health anxiety (Görgen et al., 2014). Strategies of adaptive emotional regulation can help prevent symptoms of anxiety and depression because people become able to cope with emotional situations. A link was found between higher problem solving coping mechanism, on the one hand, and lower levels of depression and anxiety symptoms, on the other hand.

Maladaptive emotions, mainly rumination and avoidance, will lead to long-term significant negative emotions. Avoidance is a maladaptive strategy that can lead to high levels of anxiety in time (Werner \& Gross, 2010). Suppression, as a maladaptative coping strategy, is detrimental to the mental health, and can lead to symptoms of anxiety and depression. Rumination is also associated with depression and anxiety in adults and young adults. Regarding rumination, the effect size was large for its relationship with depression symptoms 
and medium for its relationship with anxiety symptoms (Schäfer et al., 2017). People tried through rumination to better understand events in order to be able to prevent the risks. Blaming others represents an external attribution and it is perceived as normalizing. For subjects with high levels of health anxiety, blaming someone else is beneficial in the short-term, in the long run blaming others can affect social relationships, a commonly found occurence in health anxiety (Görgen et al., 2014).

Marcus et al. (2008), conducted a study on 198 students finding a significant correlation between maladaptative coping strategies, namely rumination, and health anxiety levels. The same study showed a direct relationship between catastrophizing, ambiguous bodily symptoms and the health anxiety level (Görgen et al., 2014). These authors confirmed the relationship between health anxiety factors and cognitive coping as well as emotion regulation strategies. Previous studies revealed that the level of health anxiety increases in situations with high levels of stress and emotional stimulation, they also observed a direct association between catastrophizing, ambiguous bodily symptoms, and health anxiety levels (Campbell-Sills et al., 2006a, b; Ehring et al., 2008).

The absence of functional coping mechanisms proved to be less important than the existance of dysfunctional emotion regulation strategies in the etiology of psychological disorders. If people suppress their emotions, then they will avoid social support. People who use this type of coping mechanism will also avoid close relationships and attachment to others. Görgen et al. (2014) as well as Marcus et al. (2008) found a positive connection between the maladaptative coping strategies of suppression, rumination, catastrophizing and the level of health anxiety.

Our study was carried out at the beginning of the epidemy in Romania, in the third week after the breakout, under very similar circumstances as in the studies wicho pointed out that since the pandemic was at its beginning information about the virus was scarce (Ho et al., 2020; Wang et al., 2020). This could have contributed to a greater level, $30 \%$, of pandemic-related anxiety symptoms (directly related to the pandemic). In his study carried out in Wuhan, Wang et al. (2020) revealed intense anxiety related to the lack of information and uncertainty related to the virus (Jungmann \& Witthöft, 2020). In their study, Wang et. al. (2020) showed that Covid-19 proves to be a massive health problem of global impact which may represent a challenge to our psychological resilience. Another study conducted by Jungmann and Witthöft (2020), was carried out in exactly the same week as our study, middle March, in Germany, and found that approximately $50 \%$ of those assessed in the study reported at least moderate levels of anxiety related to COVID-19.

Some studies particularly targeted the student population. A study analyzing a large sample of college students established that $0,9 \%$ of them had severe anxiety, $2,7 \%$ moderated and 21,3\% low levels of anxiety (Cao et al., 2020). Students' status was associated with a psychological distress related to the pandemic, including stress, anxiety and depression (Wang et al., 2020). Students and young adults up to 30 years had a higher psychological distress since schools at all levels were closed and they were in a much closer contact with updated information through social media (Qiu et al., 2020; Tian et al., 2020a). Also, older people present severe psychological symptoms more frequently related to health anxiety with regard to COVID infection (Jungmann \& Witthöft, 2020; Tian et al., 2020a). Moreover, lower levels of education were connected by the authors to a higher level of depression (Tian et al., 2020a), while a higher level of education leads to higher levels of stress, explained through an exceeding self-awareness (Qiu et al., 2020).

The purpose of the current study was to identify the psychological factors affected by the COVID-19 pandemic given the information we have about reactions during previous pandemics. We were interested in investigating the relationship between anxiety, health anxiety, depression, stress, coping strategies and COVID-19-related anxiety, occuring in the general population and among students during the pandemic. People may react in different ways when they have to face such a massive health-related risk, this is why knowing factors and mediators involved can help to better understand not only how psychological problems occur but also how they can be prevented and which interventions are useful.

Hence, it was hypothesized that:

H1. Individuals among the general population will have a higher level of COVID-19 anxiety than students.

H2. Emotional distress predicts anxiety for COVID-19, controlling for health anxiety.

H3. The relationship between health anxiety and COVID19 anxiety is mediated by maladaptive coping strategies.

The study was carried out in March, in the week between 13 - 20th of March, when the number of cases has risen from 64 to 277 in our country, and no deaths were yet registered by the National Institute of Public Health of Romania. A State of Emergency was declared on March 16, when all schools and many businesses were closed.

\section{Methods}

\section{Participants}

The participants in the present study were all aged above 18 and have not been infected by COVID-19, but they live in Timis county which was affected by the Coronavirus. The 
study was conducted on general population after the first 2 weeks of COVID-19 outbreak in Romania.

In total, 759 participants, aged between $18-70$ years old $(M=33.24 ; S D=12.17)$ have completed the participation in this study, neither of whom was involved in the design nor in the carrying out of this research. Of the 759 participants, $42.2 \%$ were female $(n=315)$ and $57.8 \%$ were male $(n=432)$. Also, $36.1 \%$ were students $(n=274)$ and $63.9 \%$ were from general population $(n=485)$.

\section{Procedure}

For the present study, the questionnaires were applied online, all subjects participated voluntarily and were asked to sign an informed consent. All participants agreed to take part in the study voluntarily and anonymously. We used an online survey and the snowball technique The online survey was first disseminated among university students and they were asked to contact other respondents. As all activities took place online, and people were at the beginning of the isolation (at home period), they were invited electronically by the authors at first, and afterwards by the existing study participants. The approval of the Ethics Committee of Univeristy regarding the study protocol has been obtained.

\section{Measures}

\section{The Short Health Anxiety Inventory}

(SHAI; Salkovskis et al., 2002) consists of 18 -items, with two subscales. The first subscale measures health anxiety, the probability of becoming ill, while the second one assesses the negative consequences if the illness occurs. The instrument offers multiple choices, with four possible statements coding from 0 to 3 . The internal consistency for this study was 0.84 .

\section{Cognitive Emotion Regulation Questionnaire}

(CERQ; (Garnefski et al., 2002, translated and validated on Romanian population by Perte \& Miclea, 2010). This scale measures the cognitive and emotional coping strategies used after experiencing negative life events. It consists of 36 items and nine subscales: self-blame, blaming others, acceptance, refocus on planning, positive refocusing, rumination, positive reappraisal, putting into perspective, and catastrophizing. Answer categories of the items range from 1 (almost never) to 5 (almost always). The internal consistencies range from $\alpha=0.75$ to $\alpha=0.87$. For the present study $\alpha=0.90$ (from $\alpha=0.72$ for catastrophizing to 0.85 for positive refocusing, rumination, positive reappraisal).

\section{The Depression Anxiety Stress Scales}

(DASS-21; (Lovibond \& Lovibond, 1995, translated and validated on Romanian population by Perţe \& Albu, 2011). This scale was designed to assess emotional distress in three subcategories: depression, anxiety and stress. It contains 21 items, scored on 3-point Likert scales, with answers from 0 (did not apply to me at all) to 3 (applied to me very much, or most of the time). The internal consistency for this study was 0.94 ( $\alpha=0.86$ for anxiety and depression, and 0.87 for stress).

\section{Coronavirus Anxiety Inventory}

Is a nine-item measure designed to assess anxiety associated with the 2019 novel CoV. Items were inspired by those used in studies to assess H1N1 (Swine flu) anxiety (Wheaton et al., 2012), Ebola virus anxiety (Blakey et al., 2015) and Zika virus anxiety (Blakey \& Abramowitz, 2017). Respondents evaluated their agreement with each item on a 5-point scale, from 0 (very little) to 4 (very much), with lower scores indicating lower COVID19-related anxiety. For this study, we prepared a translation using the back-translation technique and examined the psychometric properties for this scale. The principalaxis EFA for the total sample $(n=759)$ and the Direct Oblimin rotation revealed two single factors for this scale. The Kaiser-Meyer-Olkin (KMO) sampling adequacy was 0.826 , and the significance of Bartlett's test of sphericity, $\chi^{2}(36)=2942.11, p<0.001$, indicated that these data had adequate factorability. The EFA indicated that two factors should be extracted. Running CFA, the results confirmed the two factors solution for the scale $\left(\chi^{2}(26)=346.154\right.$, $p<0.001 ; G F I=0.900, C F I=0.890, A I C=384.154$, $R M S E A=0.127, S R M R=0.058)$. For this study, the internal consistency was 0.85 .

\section{Demographics}

We requested the participants to report age, gender, educational level, marital status, and occupation.

\section{Data Analysis}

First, descriptive statistics and Pearson correlations were analyzed among the variables included in the study by using IBM SPSS 23.0 version. Then, for testing the hypothesis, 
we used t-independent test to compare the population with regard to COVID-19 anxiety. Afterwards using hierarchical regression we analyzed symptoms of depression, anxiety and stress as predictors of COVID-19 anxiety. Finally, we used PROCESS Macro, SPSS version 3.0 (Hayes, 2018), model 4 to test the mediation relationship, and bootstrapping to identify the indirect effect in this model with confidence interval analysis (CI 95\%).

\section{Results}

\section{Individuals Among the General Population will have a Higher Level of COVID-19 Anxiety than Students}

The results confirmed that there are differences between groups, $t(757)=1.902, p<0.05, p=0.029$. People from the general population are more anxious about COVID-19 pandemic $(M=20.22, S D=7.71)$ than students $(M=19.12$, $S D=7.93)$.

\section{Emotional Distress Predicts Anxiety for COVID-19, Controlling for Health Anxiety}

We assessed the multicollinearity by testing the variance inflation factors (VIFs). Values over 10 indicate a high multicollinearity (Hair et al., 1995). For the present study $V I F=1.019$

Following the analysis of the hierarchical regression, the results found that when controlling the health anxiety variable, a high level of anxiety symptoms and stress, and a low level of depression symptoms, could predict anxiety for COVID-19. For this analysis, health anxiety was inserted in the first step. Then, in the second step, depression, anxiety and stress factors were included as predictor variables of COVID-19 anxiety.

When depression, anxiety and stress factors were included in the initial model containing health anxiety $(\mathrm{R}=0.090$, $\left.\mathrm{R}^{2}=0.008, F_{\text {change }}(1,757)=6.166, p=0.013\right)$, an explanatory plus of $R^{2}=0.070, F_{\text {change }}(3,754)=16.759, p<0.001$ was observed.

\section{The relationship Between Health Anxiety and COVID-19 Anxiety is Mediated by Maladaptive Coping Strategies}

The results presented in Tables 1 and 2 revealed that health anxiety and maladaptive strategies correlate with COVID19 anxiety. The results (Table 3 ) found that the indirect effect of maladaptive strategies on COVID-19 anxiety is different from zero, as shown by the confidence interval $(95 \% \mathrm{CI}=0.011-0.057)$ while the direct effect of health anxiety is not significant $t(756)=1.7613, p=0.076(95 \%$ $\mathrm{CI}=-0.008-0.154)$. At the same time, the results show that the total effect of the relationship is statistically significant $(95 \% \mathrm{CI}=0.022-0.188), t(759)=2.483, p<0.015$. These results support the assertion that maladaptive strategies are explanatory of the relationship between health anxiety and COVID-19-related anxiety. Thus, the results revealed a partial mediation between variables. The results suggest that at least some of this effect occurs through maladaptive strategies as mediating variable due to the significant indirect effect. In addition, the insignificant direct effect shows that at least part of this effect occurs through mechanisms other than those of the mediating variable (Fig. 1).

Table 2 Results of regression for depression, anxiety and stress as predictors of COVID-19 anxiety

\begin{tabular}{llll}
\hline Predictors & $\beta$ & $t$ & $p$ \\
\hline Step 1 & & & \\
$\quad$ Health anxiety & .090 & 2.483 & .013 \\
Step 2 & & & \\
$\quad$ Health anxiety & .052 & 1.476 & .140 \\
$\quad$ Depression & -.147 & -2.782 & .006 \\
Anxiety & .167 & 2.935 & .003 \\
Stress & .199 & 3.647 & .000 \\
\hline
\end{tabular}

$n=759 ; p<.05$ (2-tailed)
Tabel 1 Correlations between variables

\begin{tabular}{llllllll}
\hline & 1 & 2 & 3 & 4 & 5 & 6 & 7 \\
\hline Anxiety & 1 & $.710^{* *}$ & $.730^{* *}$ & $.118^{* *}$ & $.215^{* *}$ & $.448^{* *}$ & -.057 \\
Depression & $.710^{* *}$ & 1 & $.677^{* *}$ & $.063^{* *}$ & $.110^{* *}$ & $.475^{* *}$ & $-.164^{* *}$ \\
Stress & $.730^{* *}$ & $.677^{* *}$ & 1 & $.135^{* *}$ & $.229^{* *}$ & $.483^{* *}$ & -.053 \\
Health anxiety & $.118^{* *}$ & $.063^{*}$ & $.135^{* *}$ & 1 & $.090^{* *}$ & $.111^{* *}$ & -.047 \\
COVID-19 anxiety & $.215^{* *}$ & $.110^{* *}$ & $.229^{* *}$ & $.090^{* *}$ & 1 & $.256^{* *}$ & $.111^{* *}$ \\
Maladaptive strategies & $.448^{* *}$ & $.475^{* *}$ & $.483^{* *}$ & $.111^{* *}$ & $.256^{* *}$ & 1 & $.258^{* *}$ \\
Adaptive strategies & -.057 & $-.164^{* *}$ & -.053 & -.047 & $.111^{* *}$ & $.258^{* *}$ & 1 \\
\hline
\end{tabular}

$n=759 ;{ }^{* *} p<.01$ (1-tailed) ${ }^{*} p<.05$ (1-tailed) 
Table 3 Testing the mediation effect of maladaptive strategies in the relationship between health anxiety and COVID-19 anxiety

\begin{tabular}{|c|c|c|c|c|c|c|}
\hline \multirow[t]{2}{*}{ Predictor/mediator } & \multicolumn{3}{|l|}{ MS } & \multicolumn{3}{|l|}{ C-19anx } \\
\hline & Coef & $S E$ & $p$ & Coef & $S E$ & $p$ \\
\hline HA & $a-.176$ & .057 & $<.001$ & $c^{\prime} .072$ & .041 & .078 \\
\hline MS & - & - & - & $b .184$ & .026 & $<.001$ \\
\hline \multirow[t]{3}{*}{ Constant } & $i_{M} 39.820$ & .773 & $<.01$ & $i_{Y} 11.258$ & 1.174 & $<.001$ \\
\hline & \multicolumn{3}{|l|}{$R^{2}=.012$} & \multicolumn{3}{|l|}{$R^{2}=.070$} \\
\hline & \multicolumn{3}{|c|}{$\begin{array}{c}F(1,757)=9.467, \\
\quad p=<.001\end{array}$} & \multicolumn{3}{|c|}{$\begin{array}{c}F(2,756)=28.215 \\
p=<.001\end{array}$} \\
\hline
\end{tabular}

$n=759 ; \mathrm{HA}=$ Health anxiety $\mathrm{MS}=$ maladaptive strategies; C-19anx =COVID-19 anxiety

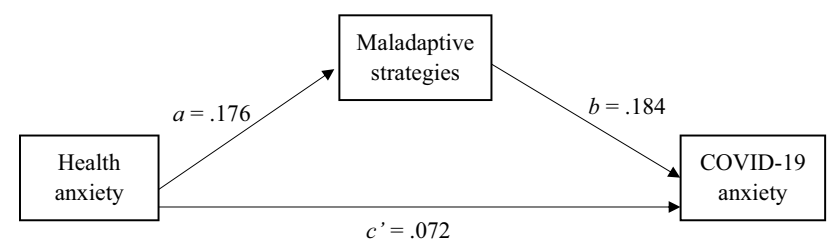

Fig. 1 Maladaptive strategies as a mediator of the relationship between health anxiety and COVID-19 anxiety

\section{Discussions}

The present study aimed to investigate the relationship between health anxiety, emotional distress, coping strategies and COVID-19-related anxiety. Results showed that the general population is more anxious when confronted with the new virus compared to students. A study conducted by Nianqi Liu et al. (2020) also found that COVID19 has a greater impact on the general population than that caused by the SARS epidemic. One possible explanation might be the fact that the participants from the general population, being adults, are more interested to access information about the coronavirus pandemic, thus getting more anxious once the sanitary emergency escalates. As similar results were also found in studies conducted on college students, researchers concluded that the results can be extrapolated to the entire population. (Görgen et al., 2014). A study in Wuhan performed by Kang et al. (2020) revealed intense anxiety due to lack of information and uncertainty related to the virus. It was also found that people aged between 30-59 have higher anxiety levels related to COVID-19 (Jungmann \& Witthöft, 2020).

Our study found that emotional distress predicts COVID-19 related anxiety, regardless of the level of hypochondria. More specifically, a high level of anxiety symptoms and stress predicts a higher level of disease related anxiety. Moreover, the results revealed that a low level of depression predicts a higher level of anxiety related to COVID-19. Pre-existing studies have shown that there is a connection between COVID-19 and various psychological disorders including anxiety, depression, panic disorder and health concerns (Cao et al., 2020; Qiu et al., 2020; Zhang et al., 2020). These results indicate a high level of virus anxiety which was retrospectively assessed. Previous studies have shown that more than $50 \%$ of those investigated experienced anxiety during epidemics or pandemics. Recent studies on Chinese students and also on the general population found that $25-35 \%$ of the participants have anxiety symptoms and report high levels of stress (Cao et al., 2020; Wang et al., 2020). Covid-19 related anxiety may result in stress and avoidance, which can lead to inefficient preventive behavior that can be unconstructive for the person and hence leading to negative consequences, such as pessimism and eventually depression (Qiu et al., 2020; Wang et al., 2020). The low level of depression symptoms which was found in our study could be due to the fact that our study was performed in the first weeks of the pandemic when high levels of anxiety symptoms were registered due to insufficient disease related knowledge and many uncertainties concerning the further evolution of the sanitary crisis, thus predicting high levels of stress. These circumstances will challenge the individuals coping strategies, which regardless of being positive or negative, through different mechanisms (exhaustion or rumination and catastrophizing) are related to depression, even if at this early stage of evolution, it was yet at a low level.

Our results also showed that high levels of anxiety symptoms, stress and low levels of depression symptoms can be predictive of COVID-19 anxiety. Also, we found that $0.8 \%$ of the dispersion of the results for the COVID-19 anxiety is due to health anxiety and that this percentage increases to $7 \%$ when considering emotional distress. Stress can be perceived as a continuous hyperactive status which creates difficulties for the person when dealing with challenging life events. Moreover, anxiety can appear as a consequence of a physical threat, as was the case during the sanitary crisis. A study by Bakio and Korkmaz (2020) showed a correlation between fear of COVID-19, depression, anxiety and stress. Anxiety concerning the infection with the new coronavirus, much more contagious, can produce stress, anxiety, and depression. The authors suggest the possibility for emotional 
distress to predict COVID-19 anxiety, as also revealed by our study. Uncertainty, fear, can adversely affect the positivity of individuals can increase virus related anxiety.

Stressful events experienced during the sanitary crisis made some people adopt positive coping strategies in order to handle the situation. A significant correlation between maladaptive coping strategies and health anxiety is found in several studies (Görgen et al., 2014). However, the statistical analysis in our study revealed a positive correlation between the adaptive coping strategies and virus' related anxiety. The literature showed that positive coping can have a negative impact on life quality due to a possible exhaustion effect (Crangle et al., 2020).

Moreover, the present study aimed to investigate the relationship between health anxiety, coping strategies and COVID-19 related anxiety. Taha et al. (2014) when analyzing the H1N1 pandemic in 2009, had shown that intolerance to uncertainty can predict high levels of anxiety. Mediators in this relationship were found to be the evaluation of stressors and the coping strategies (Tian et al., 2020b). The results of our study are in line with those from previous studies which emphasize that dysfunctional emotion regulation strategies have higher importance in psychological functioning (Görgen et al., 2014). In our study, we found that maladaptive coping strategies explain the relationship between hypochondria and anxiety concerning the new coronavirus. These results support the literature according to which health anxiety is associated with cognitive coping and emotion regulation. Maladaptive strategies have been found to be associated with psychological problems, rumination and catastrophizing being directly related to health anxiety (Görgen et al., 2014). In their study Görgen et al. (2014) found that people tried to better understand events through rumination in order to prevent risks. Blaming the other person represents an external attribution and it is perceived as normalizing. In subjects with high levels of health anxiety blaming someone is beneficial in the short-term. On the other hand, this blaming can affect social relationships, a phenomenon that is often encountered in health anxiety.

The irrational thoughts and experienced fear in the case of hypochondria can increase feelings of guilt and continuous preoccupation with ruminative thoughts when confronted with the sanitary crisis during these times. This in turn could predict higher levels of coronavirus-related anxiety. Also, the way a person positions themselves to this event, as being the worst thing that they could ever experience, as well as the belief that the situation is far more serious for them than for anyone else, can lead to high levels of COVID-19-related anxiety. Moreover, by choosing negative coping strategies the person can blame others for what is happening, thus becoming more anxious concerning this disease due to the perceived lack of control over it.
The insignificant direct effect shows revealed by our results shows that at least part of this effect occurs through mechanisms other than those of the mediating variable. Other studies have revealed some possible psychological mediating variables which could explain the relationship between health anxiety and COVID-19 anxiety (Cheng et al., 2013; Ebrahim et al., 2020; Guo et al., 2020; Kesavayuth et al., 2019; Sigurvinsdottir et al., 2020). A study conducted by Ebrahim et al. (2020), showed a correlation between the frequency of information seeking on the topic of the pandemic and higher levels of anxiety symptoms. Moreover, the exposure to media sources leads to greater mental health related problems as a study performed on Chinese adult population revealed (Guo et al., 2020). Negative information seeking on the topic of the pandemic and an external locus of control was found to be associated with higher anxiety symptoms (Sigurvinsdottir et al., 2020). Other studies (Cheng et al., 2013; Kesavayuth et al., 2019) revealed that a higher internal locus of control decreases anxiety symptoms and can be put in connections with researching information about health. This information researching may lead to raising the level of emotional distress but as a positive effect it encourages health related activities.

The results of this study are in line with previous studies which emphasize that the presence of maladaptive coping strategies plays a more important role in psychological disorders than the lack of adaptive mechanisms (Görgen et al., 2014). Future studies may analyze adaptive and maladaptive coping strategies in relation to health anxiety and coronavirus anxiety.

\section{Conclusions}

Our study was performed at the beginning of the pandemic and it provides new knowledge to the understanding of how COVID-19 anxiety occurs, offering at the same time hints for prevention and intervention strategies. Until now, as far as we know, studies have investigated the effect that COVID19-related anxiety has on emotional distress. The present study analysed the relationship between COVID-19-related anxiety and depression symptoms, anxiety symptoms, and stress in reverse, pointing out that emotional distress predicts COVID-19 anxiety, as suggested by the study led by Bakio and Korkmaz (2020).

Our results revealed associations between emotional distress and COVID-19 related anxiety. Also, we found that maladaptive coping strategies explain the relationship between hypochondria and coronavirus related anxiety. The results of this study shed new light on the psychological aspects of the current sanitary crisis and contribute to the understanding of the way people relate to this disease. 
Besides medical strategies, a coordinated psychological intervention should be provided to all those in need in such major disasters. Our study may help identify risk patterns, help promote interventions to reduce psychological problems associated with the pandemic mainly through psychoeducation, provided through online interventions. Psychoeducation could be extended to counseling via smartphone/laptops/tablets, which could be leading to people better coping with mental health problems during these times. Psychological intervention can lower maladaptive coping strategies as maladaptive coping was found to be associated with an increased level of psychological problems.

Given the specific conditions during the pandemic, more precisely the physical distancing, psychological assistance can be carried out exclusively online. Offering education to individuals and families could facilitate a better understanding of the possible ways to handle the current situation (Goian, 2013). In order to do this, psychologists should improve their skills in working with online technology and delivering assistance online. In Romania most psychological departments of the universities offered psychological hotlines during the lock-down, and have continued afterwards to provide psychological interventions to all those affected or in need during the entire period.

\section{Limitations}

Participants were recruited through voluntary selection and the measurements took place at a single time point. Another limitation is that we obtained self-reported levels of emotional distress and COVID-19 related anxiety. At that point in time our opportunities were limited and we were under time pressure so we decided to use the snowball sampling strategy. Also, data was collected online, so people with certain educational and financial possibilities probably had easier access to the completion of the questionnaires. Another limit is given by the relatively low number of participants, thus the results cannot be generalized to the entire population. However, the vast majority of the participants encompasses the general population.

Data Availability The data that support the findings of this study are available from the corresponding author on request.

\section{Declarations}

Human and Animal Rights All procedures performed in studies involving human participants were in accordance with the ethical standards of the West University of Timisoara, Romania and with the 1964 Helsinki Declaration and its later amendments or comparable ethical standards.
Informed Consent Informed consent was obtained from all individual adult participants included in the study.

Conflict of Interest The authors declare that they have no conflict of interest.

\section{References}

Asmundson, G. J. G., \& Taylor, S. (2020). How health anxiety influences responses to viral outbreaks like COVID-19: What all decision-makers, health authorities, and health care professionals need to know. In Journal of Anxiety Disorders, 71, $102211 \mathrm{https}$ ://doi. org/10.1016/j.janxdis.2020.102211

Asmundson, G. J. G., Abramowitz, J. S., Richter, A. A., \& Whedon, M. (2010). Health anxiety: Current perspectives and future directions. In Current Psychiatry Reports, 12 (4), 306-312). https://doi.org/ 10.1007/s11920-010-0123-9

Bakio, F., \& Korkmaz, O. (2020). Fear of COVID-19 and Positivity : Mediating Role of Intolerance of Uncertainty, Depression, Anxiety, and Stress.

Banerjee, D. D. (2020). The other side of COVID-19: Impact on obsessive compulsive disorder (OCD) and hoarding. In Psychiatry Research, 288. Elsevier Ireland Ltd. https://doi.org/10.1016/j. psychres.2020.112966

Blakey, S. M., \& Abramowitz, J. S. (2017). Psychological predictors of health anxiety in response to the Zika virus. Journal of Clinical Psychology in Medical Settings, 24(3-4), 270-278. https://doi. org/10.1007/s10880-017-9514-y

Blakey, S. M., Reuman, L., Jacoby, R. J., \& Abramowitz, J. S. (2015). Tracing "Fearbola": Psychological predictors of anxious responding to the threat of Ebola. Cognitive Therapy and Research, 39(6), 816-825. https://doi.org/10.1007/s10608-015-9701-9

Campbell-Sills, L., Barlow, D. H., Brown, T. A., \& Hofmann, S. G. (2006a). Effects of suppression and acceptance on emotional responses of individuals with anxiety and mood disorders. Behaviour Research and Therapy, 44(9), 1251-1263. https://doi.org/10. 1016/j.brat.2005.10.001

Campbell-Sills, L., Barlow, D. H., Brown, T. A., \& Hofmann, S. G. (2006b). Acceptability and suppression of negative emotion in anxiety and mood disorders. Emotion, 6(4), 587-595. https://doi. org/10.1037/1528-3542.6.4.587

Cao, W., Fang, Z., Hou, G., Han, M., Xu, X., Dong, J., \& Zheng, J. (2020). The psychological impact of the COVID-19 epidemic on college students in China. Psychiatry Research, 287, 112934. https://doi.org/10.1016/j.psychres.2020.112934

Cheng, S. K. W., Wong, C. W., Tsang, J., \& Wong, K. C. (2004). Psychological distress and negative appraisals in survivors of severe acute respiratory syndrome (SARS). Psychological Medicine, 34(7), 1187-1195. https://doi.org/10.1017/S0033291704002272

Cheng, C., Cheung, S. F., Chio, J.H.-M., \& Chan, M.-P.S. (2013). Cultural meaning of perceived control: A meta-analysis of locus of control and psychological symptoms across 18 cultural regions. Psychological Bulletin, 139(1), 152-188. https://doi.org/10.1037/ a0028596

Chong, M. Y., Wang, W. C., Hsieh, W. C., Lee, C. Y., Chiu, N. M., Yeh, W. C., Huang, T. L., Wen, J. K., \& Chen, C. L. (2004). Psychological impact of severe acute respiratory syndrome on health workers in a tertiary hospital. British Journal of Psychiatry, 185, 127-133. https://doi.org/10.1192/bjp.185.2.127

Crangle, C. J., Torbit, L. A., Ferguson, S. E., \& Hart, T. L. (2020). Dyadic coping mediates the effects of attachment on quality of life among couples facing ovarian cancer. Journal of 
Behavioral Medicine, 43(4), 564-575. https://doi.org/10.1007/ s10865-019-00096-3

Decret semnat de Președintele României, domnul Klaus Iohannis, privind instituirea stării de urgență pe teritoriul României. (DPR). Retrieved July 29, 2020, from https://www.presidency.ro/ro/ media/decret-semnat-de-presedintele-romaniei-domnul-klausiohannis-privind-instituirea-starii-de-urgenta-pe-teritoriul-roman iei

Ebrahim, A. H., Saif, Z. Q., Buheji, M., AlBasri, N., Al-Husaini, F. A., \& Jahrami, H. (2020). COVID-19 information-seeking behavior and anxiety symptoms among parents. OSP J. Health Care Med., $1,1-9$.

Ehring, T., Fischer, S., Schnülle, J., Bösterling, A., \& Tuschen-Caffier, B. (2008). Characteristics of emotion regulation in recovered depressed versus never depressed individuals. Personality and Individual Differences, 44(7), 1574-1584. https://doi.org/10. 1016/j.paid.2008.01.013

Eisma, M. C., Boelen, P. A., \& Lenferink, L. I. M. (2020). Prolonged grief disorder following the Coronavirus (COVID-19) pandemic. In Psychiatry Research, 288. https://doi.org/10.1016/j.psychres. 2020.113031

Garnefski, N., Kraaij, V., \& Spinhoven, P. (2002). Manual for the use of the Cognitive Emotion Regulation Questionnaire. Leiderdorp, The Netherlands: DATEC.

Goian, C. (2013). Teaching social work practice. Ed. Pro Universitaria.

Görgen, S. M., Hiller, W., \& Witthöft, M. (2014). Health anxiety, cognitive coping, and emotion regulation: A latent variable approach. International Journal of Behavioral Medicine, 21(2), 364-374. https://doi.org/10.1007/s12529-013-9297-y

Guo, J., Feng, X. L., Wang, X. H., \& van IJzendoorn, M. H. (2020). Coping with COVID-19: Exposure to COVID-19 and negative impact on livelihood predict elevated mental health problems in Chinese adults. International Journal of Environmental Research and Public Health, 17(11), 3857. https://doi.org/10.3390/ijerp h17113857

Hair, J. F., Anderson, R. E., Tatham, R. L., \& Black, W. C. (1995). Multivariate data analysis. Englewood Cliffs, NJ: Prentice-Hall.

Hayes, A. F. (2018). Introduction to Mediation, Moderation, and Conditional Process Analysis, Second Edition: A Regression-Based Approach.

Ho, C. S., Chee, C. Y., \& Ho, R. C. (2020). Mental Health Strategies to Combat the Psychological Impact of COVID-19 Beyond Paranoia and Panic. Annals of the Academy of Medicine, Singapore, 49(1), 1-3.

Huremović, D. (Ed.). (2019). Psychiatry of pandemics: A mental health response to infection outbreak. Springer.

IHR Emergency Committee on Novel Coronavirus (2019-nCoV) (IHR). Retrieved July 29, 2020, from https://www.who.int/dg/ speeches/detail/who-director-general-s-statement-on-ihr-emerg ency-committee-on-novel-coronavirus-(2019-ncov)

Jungmann, S. M., \& Witthöft, M. (2020). Health anxiety, cyberchondria, and coping in the current COVID-19 pandemic: Which factors are related to coronavirus anxiety? Journal of Anxiety Disorders, 73, 102239. https://doi.org/10.1016/j.janxdis.2020.102239

Kang, L., Li, Y., Hu, S., Chen, M., Yang, C., Yang, B. X., Wang, Y., Hu, J., Lai, J., Ma, X., Chen, J., Guan, L., Wang, G., Ma, H., \& Liu, Z. (2020). The mental health of medical workers in Wuhan, China dealing with the 2019 novel coronavirus. In The Lancet Psychiatry, 7(3), e14. https://doi.org/10.1016/S2215-0366(20) 30047-X

Kesavayuth, D., Poyago-Theotoky, J., Tran, D. B., \& Zikos, V. (2019). Locus of control, health and healthcare utilization. Economic Modelling. https://doi.org/10.1016/j.econmod.2019.06.014

Kim, H. C., Yoo, S. Y., Lee, B. H., Lee, S. H., \& Shin, H. S. (2018). Psychiatric findings in suspected and confirmed middle east respiratory syndrome patients quarantined in hospital: A retrospective chart analysis. Psychiatry Investigation, 15(4), 355-360. https://doi.org/10.30773/pi.2017.10.25.1

Lazarus, R. S. (1999). Stress and emotion: A new synthesis. New York: Springer Publishing Co.

Lazarus, R. S. (2006). Stress and emotion: A new synthesis. Springer Publishing Company.

Liu, N., Zhang, F., Wei, C., Jia, Y., Shang, Z., Sun, L., Wu, L., Sun, Z., Zhou, Y., Wang, Y., \& Liu, W. (2020). Prevalence and predictors of PTSS during COVID-19 outbreak in China hardest-hit areas: Gender differences matter. Psychiatry Research, 287, 112921. https://doi.org/10.1016/j.psychres.2020.112921

Lovibond, P. F., \& Lovibond, S. H. (1995). The structure of negative emotional states: Comparison of the Depression Anxiety Stress Scales (DASS) with the Beck Depression and Anxiety Inventories. Behaviour Research and Therapy, 33(3), 335-343. https://doi.org/ 10.1016/0005-7967(94)00075-U

Marcus, D. K., Hughes, K. T., \& Arnau, R. C. (2008). Health anxiety, rumination, and negative affect: A mediational analysis. Journal of Psychosomatic Research, 64(5), 495-501. https://doi.org/10. 1016/j.jpsychores.2008.02.004

Perţe,. A, \& Albu, M. (2011). DASS 21-R. Adaptarea si standardizarea DASS pe populatia din Romania [DASS 21 - R. DASS adaptation and standardization on the Romanian population], Cluj-Napoca, Edit. ASCR, 63 pp.

Perte, A. \& Miclea, M. (2010). Chestionarul de coping cognitivemotional - CERQ. Adaptarea si standardizarea pe populatia din Romania [Cognitive-emotional coping questionnaire - CERQ. Adaptation and standardization on the Romanian population]. Ed. ASCR.

Qiu, J., Shen, B., Zhao, M., Wang, Z., Xie, B., \& Xu, Y. (2020). A nationwide survey of psychological distress among Chinese people in the COVID-19 epidemic: Implications and policy recommendations. In General Psychiatry, 33(2). https://doi.org/10.1136/ gpsych-2020-100213

Salkovskis, P. M., Rimes, K. A., Warwick, H. M. C., \& Cclark, D. M. (2002). The health anxiety inventory: development and validation of scales for the measurement of health anxiety and hypochondriasis. Psychological Medicine, 32(05). https://doi.org/10.1017/ s0033291702005822

Schäfer, J. Ö., Naumann, E., Holmes, E. A., Tuschen-Caffier, B., \& Samson, A. C. (2017). Emotion regulation strategies in depressive and anxiety symptoms in youth: A meta-analytic review. Journal of Youth and Adolescence, 46(2), 261-276. https://doi.org/10. 1007/s10964-016-0585-0

Sigurvinsdottir, R., Thorisdottir, I. E., \& Gylfason, H. F. (2020). The impact of COVID-19 on mental health: The role of locus on control and internet use. International Journal of Environmental Research and Public Health, 17(19), 6985. https://doi.org/10. 3390/ijerph17196985

Taha, S., Matheson, K., Cronin, T., \& Anisman, H. (2014). Intolerance of uncertainty, appraisals, coping, and anxiety: The case of the 2009 H1N1 pandemic. British Journal of Health Psychology, 19(3), 592-605. https://doi.org/10.1111/bjhp.12058

Taylor, S., \& Asmundson, G. J. G. (2004). Treating health anxiety: A cognitive-behavioral approach. New York: Guilford.

Tian, F., Li, H., Tian, S., Yang, J., Shao, J., \& Tian, C. (2020a). Psychological symptoms of ordinary Chinese citizens based on SCL-90 during the level I emergency response to COVID-19. Psychiatry Research, 288, 112992. https://doi.org/10.1016/j.psychres.2020. 112992

Wang, C., Pan, R., Wan, X., Tan, Y., Xu, L., Ho, C. S., \& Ho, R. C. (2020). Immediate psychological responses and associated factors during the initial stage of the 2019 coronavirus disease (COVID19) epidemic among the general population in China. International Journal of Environmental Research and Public Health, 17(5). https://doi.org/10.3390/ijerph17051729 
Werner, K., \& Gross, J. J. (2010). Emotion regulation and psychopathology: A conceptual framework. In A. M. Kring \& D. M. Sloan (Eds.), Emotion regulation and psychopathology: A transdiagnostic approach to etiology and treatment (pp. 13-37). The Guilford Press.

Wheaton, M. G., Abramowitz, J. S., Berman, N. C., Fabricant, L. E., \& Olatunji, B. O. (2012). Psychological predictors of anxiety in response to the H1N1 (swine flu) pandemic. Cognitive Therapy and Research, 36(3), 210-218. https://doi.org/10.1007/ s10608-011-9353-3

World Health Organization (WHO) (2015). Summary of probable SARS cases with onset of illness from 1 November 2002 to 31 July 2003.

World Health Organization (WHO) (2020a). Coronavirus. Retrieved July 29, 2020, from https://www.who.int/health-topics/coronavirus\#tab=tab_1

World Health Organization (WHO) (2020b). Emerging respiratory viruses, including COVID-19: methods for. (n.d.). Retrieved July 29, 2020, from https://openwho.org/courses/introduction-to-ncov
World Health Organization (WHO) (2020c). Middle East respiratory syndrome coronavirus (MERS-CoV). WHO. http://www.who.int/ emergencies/mers-cov/en/

Wu, K. K., Chan, S. K., \& Ma, T. M. (2005). Posttraumatic stress, anxiety, and depression in survivors of severe acute respiratory syndrome (SARS). Journal of Traumatic Stress, 18(1), 39-42. https://doi.org/10.1002/jts.20004

Zhang, S. X., Wang, Y., Rauch, A., \& Wei, F. (2020). Unprecedented disruption of lives and work: Health, distress and life satisfaction of working adults in China one month into the COVID-19 outbreak. Psychiatry Research, 288, 112958. https://doi.org/10. 1016/j.psychres.2020.112958

Publisher's Note Springer Nature remains neutral with regard to jurisdictional claims in published maps and institutional affiliations. 